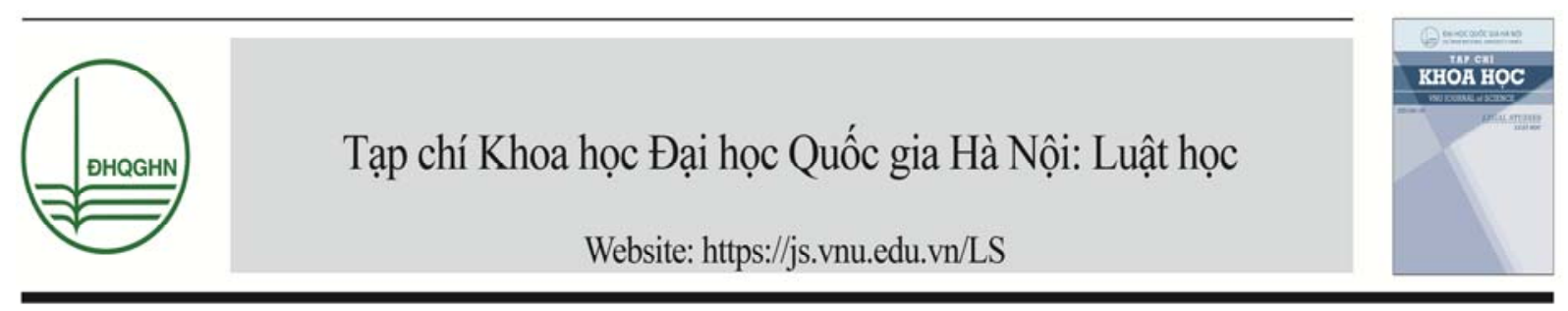

\title{
Nghiên cứu một số quy định đặc thù về các giai đoạn tố tụng đối với pháp nhân trong Bộ luật tố tụng hình sự năm 2015 và một số kiến nghị
}

\author{
Trịnh Quốc Toản* \\ Khoa Luật, Đại học Quốc gia Hà Nội, 144 Xuân Thủy, Cầu Giấy, Hà Nội, Việt Nam \\ Ngày nhận 05 tháng 12 năm 2018 \\ Chỉnh sửa ngày 20 tháng 12 năm 2018; Chấp nhận đăng ngày 24 tháng 12 năm 2018
}

\begin{abstract}
Tóm tắt: Để đáp ứng yêu cầu đấu tranh phòng ngừa và chống tội phạm trong thời kỳ mới, nhà nước Việt Nam lần đầu tiên đã quy định về trách nhiệm hình sự của pháp nhân thương mại trong Bộ luật hình sự năm 2015 (sửa đổi, bổ sung năm 2017), đồng thời cũng quy định về thủ tục truy cứu trách nhiệm hình sự đối với pháp nhân trong Bộ luật tố tụng hình sự năm 2015. Tác giả bài viết này đã nghiên cứu và phân tích các quy định của Bộ luật Tố tụng hình sự năm 2015 về thủ tục tố tụng hình sự đối với pháp nhân để chỉ ra một số điểm bất cập của chúng, đồng thời đã đề xuất một số kiến nghị cụ thể nhằm hoàn thiện các quy định ấy. Bài viết này là phần tiếp theo của bài viểt đã đăng ở Tạp chí Khoa học, Đại học Quốc gia Hà Nội, Luật học, Tập 34, Số 3 (2018).

Tù khóa: Tố tụng hình sự, Bộ luật Tố tụng hình sự năm 2015, pháp nhân thương mại, trách nhiệm hình sự của pháp nhân.
\end{abstract}

Trách nhiệm hình sự của pháp nhân là vấn đề không phải là mới trong luật hình sự (LHS) của nhiều nước $[1,2]$. Ở Việt Nam, lần đầu tiên trong lịch sử, Bộ luật Hình sự (BLHS) và Bộ luật Tố tụng hình sự (BLTTHS) năm 2015 đã quy định về trách nhiệm hình sự (TNHS); trình tự thủ tục tố tụng hình sự đối với pháp nhân. Đây là sự đổi mới tư duy về tội phạm và hình phạt, về cơ sở của TNHS, khắc phục những bất cập, hạn chế trong thực tiễn, nhằm đáp ứng yêu cầu phòng, chống tội phạm trong tình hình mới, nhất là đối với các hành vi vi phạm nghiêm trọng pháp luật về kinh tế và môi trường của pháp nhân và để bảo đảm sự thống nhất chung của hệ thống pháp luật [2].

Tiếp theo bài viết "Nghiên cứu một số quy định đặc thù về thủ tục tố tụng hình sự đối với pháp nhân trong BLTTHS năm 2015" [3] trong bài viết này, tác giả tiếp tục đề cập đến một số quy định đặc thù của BLTTHS năm 2015 nhưng liên quan trực tiếp đến từng giai đoạn tố tụng đối với pháp nhân và đề xuất một số kiến nghị nhằm tiếp tục hoàn thiện những quy định này trong BLTTHS năm 2015.

\footnotetext{
*ĐT.: 84-24-37547512.

Email: quoctoan@vnu.edu.vn.

https://doi.org/10.25073/2588-1167/vnuls.4187
} 


\section{Khởi tố vụ án, thay đổi, bổ sung quyết định khởi tố vụ án hình sự đối với pháp nhân}

\subsection{Khởi tố vu án hình sự đối với pháp nhân}

Khởi tố vụ án hình sự (VAHS) là giai đoạn bắt đầu của quá trình tố tụng hình sự để giải quyết vụ án. Trong giai đoạn này các cơ quan có thẩm quyền tiến hành tố tụng có nhiệm vụ xác định sự việc có hay không có dấu hiệu của tội phạm để khởi tố hay không khởi tố VAHS. Cũng như quy định đối với với cá nhân, khi xác định có dấu hiệu của tội phạm do pháp nhân thực hiện và không thuộc những trường hợp không được khởi tố VAHS theo Điều 157 BLTTHS năm 2015 thì cơ quan nhà nước có thẩm quyền tiến hành tố tụng ra quyết định khởi tố VAHS (khoản 1 Điều 432 BLTTHS năm 2015). Điều 143 BLTTHS năm 2015 quy định việc xác định dấu hiệu của tội phạm dựa vào các căn cứ: i) Tố giác của cá nhân; ii) Tin báo của cơ quan, tổ chức, cá nhân; iii) Tin báo trên phương tiện thông tin đại chúng; iv) Kiến nghị khởi tố của cơ quan nhà nước; v) Cơ quan có thẩm quyền tiến hành tố tụng trực tiếp phát hiện dấu hiệu tội phạm; vi) Người phạm tội tự thú.

Điều 153 BLTTHS năm 2015 quy định chung về các cơ quan nhà nước có thẩm quyền khởi tố VAHS đối với cá nhân và với pháp nhân, đó là: i) Cơ quan điều tra (CQĐT) quyết định khởi tố VAHS đối với tất cả vụ việc có dấu hiệu tội phạm, trừ những vụ việc do cơ quan được giao nhiệm vụ tiến hành một số hoạt động điều tra, Viện kiểm sát (VKS), Hội đồng xét xử đang thụ lí, giải quyết quy định tại các khoản 2, 3 và 4 Điều này; ii) Cơ quan được giao nhiệm vụ tiến hành một số hoạt động điều tra ra quyết định khởi tố VAHS trong trường hợp quy định tại Điều 164 của BLTTHS năm 2015; iii) VKS ra quyết định khởi tố VAHS trong trường hợp: Thứ nhất, VKS hủy bỏ quyết định không khởi tố VAHS của CQĐT, cơ quan được giao nhiệm vụ tiến hành một số hoạt động điều tra; Thư hai, VKS trực tiếp giải quyết tố giác, tin báo về tội phạm, kiến nghị khởi tố; Thú $b a$, VKS trực tiếp phát hiện dấu hiệu tội phạm hoặc theo yêu cầu khởi tố của Hội đồng xét xử; iv) Hội đồng xét xử ra quyết định khởi tố hoặc yêu cầu VKS khởi tố VAHS nếu qua việc xét xử tại phiên tòa mà phát hiện có việc bỏ lọt tội phạm.

Tuy nhiên, cũng cần lưu ý rằng, thẩm quyền khởi tố VAHS đối với cá nhân có những nội dung khác so với thẩm quyền khởi tố VAHS đối với pháp nhân. Về thẩm quyền khởi tố VAHS đối với pháp nhân, thì "ngoài CQĐT, VKS, không phải tất cả các cơ quan nhà nước có thẩm quyền khởi tố VAHS nêu trên đều có thẩm quyền khởi tố VAHS đối với pháp nhân, mà chỉ cơ quan nào mà phạm vi hoạt động chuyên môn của họ có trách nhiệm và khả năng phát hiện tội phạm do pháp nhân thực hiện có liên quan đến hoạt động của họ mới có quyền khởi tố VAHS đối với pháp nhân khi có căn cứ khởi tố quy định tại Điều 143 BLTTHS" [4]. Bởi vì theo Điều 76 của BLHS năm 2015 (sửa đổi năm 2017), pháp nhân chỉ phải chịu TNHS đối với các tội phạm cụ thể được quy định tại 33 điều luật về tội phạm (các điều 188, 189, 190, 191, 192, 193, 194, 195, 196, 200, 203, $209,210,211,213,216,217,225,226,227$, $232,234,235,237,238,239,242,243,244$, $245,246,300$ và 324$)$.

Luật Tổ chức CQĐT hình sự năm 2015 quy định cụ thể thẩm quyền của một số cơ quan nhà nước có thẩm quyền khởi tố VAHS đối với một số tội phạm do pháp nhân thực hiện. Cụ thể, Bộ đội biên phòng khi thực hiện nhiệm vụ trong lĩnh vực quản lí của mình mà phát hiện tội phạm quy định tại một trong các điều 188, 189, 192, 193, 195, 227, 235, 242 của BLHS năm 2015 do pháp nhân thực hiện xảy ra trong khu vực biên giới trên đất liền, bờ biển, hải đảo và các vùng biển do Bộ đội biên phòng quản lí thì có quyền khởi tố VAHS đối với pháp nhân (Điều 32). Cơ quan Hải quan khi thực hiện nhiệm vụ trong lĩnh vực quản lí của mình mà phát hiện tội phạm quy định tại một trong các điều 188,189 và 190 của BLHS năm 2015 do pháp nhân thực hiện thì có quyền khởi tố VAHS đối với pháp nhân (Điều 33). Cơ quan Kiểm lâm khi thực hiện nhiệm vụ trong lĩnh vực quản lí của mình mà phát hiện tội phạm quy định tại một trong các điều 232, 243, 244, 245 của BLHS năm 2015 thì cũng có quyền khởi tố pháp nhân (Điều 34). Các đơn vị 
thuộc lực lượng Cảnh sát biển khi thực hiện nhiệm vụ trong lĩnh vực quản lí của mình mà phát hiện tội phạm quy định tại một trong các điều 188, 189, 227, 235, 237, 242 của BLHS năm 2015 do pháp nhân thực hiện xảy ra trên các vùng biển và thềm lục địa của nước Cộng hòa xã hội chủ nghĩa Việt Nam do lực lượng Cảnh sát biển quản lí thì cũng được quyền khởi tố VAHS đối với pháp nhân (Điều 35). Cơ quan Kiểm ngư khi thực hiện nhiệm vụ trong lĩnh vực quản lí của mình mà phát hiện tội phạm quy định tại một trong các điều 242, 244, 245, 246 của BLHS năm 2015 do pháp nhân thực hiện xảy ra trên các vùng biển và thềm lục địa của nước Cộng hòa xã hội chủ nghĩa Việt Nam do Kiểm ngư quản lí có quyền khởi tố VAHS đối với pháp nhân (Điều 36).

\subsection{Quyết định khởi tố vu án hình sư, thay đổi, bổ sung quyết định khởi tố vu án hình sụ đối với pháp nhân}

Khi có dấu hiệu của tội phạm các cơ quan nhà nước có thẩm quyền phải ra quyết định khởi tố VAHS. Cũng giống như quyết định khởi tố VAHS đối với cá nhân, quyết định khởi tố VAHS đối với pháp nhân cũng áp dụng các quy định tại Điều 154 BLTTHS năm 2015.

Quyết định khởi tố VAHS phải ghi rõ căn cứ khởi tố, điều, khoản của BLHS năm 2015 được áp dụng để khởi tố vụ án, số, ngày, tháng, năm, địa điểm ban hành quyết định khởi tố VAHS; họ tên, chức vụ, chữ kí của người ban hành quyết định khởi tố VAHS và đóng dấu.

Trong thời hạn 24 giờ kể từ khi ra quyết định khởi tố VAHS, VKS phải gửi quyết định đó đến CQĐT có thẩm quyền để tiến hành điều tra.

Trong thời hạn 24 giờ kể từ khi ra quyết định khởi tố VAHS, CQĐT, cơ quan được giao nhiệm vụ tiến hành một số hoạt động điều tra phải gửi quyết định đó kèm theo tài liệu liên quan đến VKS có thẩm quyền để kiểm sát việc khởi tố.

Trong thời hạn 24 giờ kể từ khi ra quyết định khởi tố VAHS, Tòa án phải gửi quyết định đó kèm theo tài liệu liên quan đến VKS cùng cấp.
Trong trường hợp khi có căn cứ xác định tội phạm đã khởi tố không đúng với hành vi phạm tội đã xảy ra thì CQĐT, cơ quan được giao nhiệm vụ tiến hành một số hoạt động điều tra, VKS ra quyết định thay đổi quyết định khởi tố VAHS, ví dụ, Công ty Cổ phần X bị khởi tố về tội buôn lậu theo Điểm b Khoản 6 Điều 188 BLHS năm 2015, nhưng trong quá trình điều tra CQĐT có đủ chứng cứ xác định hành vi phạm tội của Công ty cổ phần $X$ cấu thành tội buôn bán hàng cấm theo Điểm $\mathrm{b}$ Khoản 5 Điều 190 BLHS năm 2015. Trong trường hợp này CQĐT ra quyết định thay đổi quyết định khởi tố vụ án theo tội danh mới.

Trong quá trình điều tra nếu xác định pháp nhân còn thực hiện hành vi phạm tội khác chưa bị khởi tố thì CQĐT ra quyết định bổ sung quyết định khởi tố VAHS, ví dụ Doanh nghiệp A bị khởi tố về tội trốn thuế theo Điểm a Khoản 5 Điều 200 BLHS năm 2015, nhưng trong quá trình điều tra, CQĐT phát hiện Doanh nghiệp này còn thực hiện hành vi phạm tội sản xuất, buôn bán hàng giả theo Điểm $\mathrm{b}$ Khoản 5 Điều 192 BLHS năm 2015. Trong trường hợp này CQĐT ra quyết định bổ sung quyết định khởi tố Doanh nghiệp $\mathrm{A}$ về tội sản xuất, buôn bán hàng giả nêu trên.

Để bảo đảm việc thực hiện nghiêm chỉnh pháp luật đối với việc thay đổi, bổ sung quyết định khởi tố VAHS đối với pháp nhân, CQĐT, cơ quan được giao nhiệm vụ tiển hành một số hoạt động điều tra phải gửi quyết định thay đổi, bổ sung quyết định khởi tố VAHS kèm theo các tài liệu có liên quan cho VKS cùng cấp hoặc VKS có thẩm quyền để thực hiện chức năng kiểm sát việc tuân theo pháp luật đối với quyết định thay đổi, bổ sung quyết định khởi tố VAHS.

Trong trường hợp VKS ra quyết định thay đổi hoặc bổ sung quyết định khởi tố VAHS thì trong thời hạn 24 giờ kể từ khi ra quyết định thay đổi hoặc bổ sung quyết định khởi tố VAHS, VKS phải gửi cho CQĐT để tiến hành điều tra. 


\section{Khởi tố bị can, thay đổi, bổ sung quyết định khởi tố bị can đối với pháp nhân}

\subsection{Khởi tố bị can đối với pháp nhân}

Khởi tố bị can là việc CQĐT, VKS, cơ quan được giao tiến hành một số hoạt động điều tra quyết định khởi tố hình sự đối với pháp nhân khi có đủ căn cứ cho rằng pháp nhân đã thực hiện hành vi mà BLHS quy định là tội phạm. Như vậy, căn cứ để các cơ quan có thẩm quyền ra quyết định khởi tố VAHS đối với pháp nhân khi đã thu thập được đầy đủ các chứng cứ chứng minh họ đã thực hiện hành vi phạm tội.

Khởi tố bị can đối với pháp nhân cũng như đối với cá nhân do người có chức vụ trong các cơ quan CQĐT, VKS, cơ quan được giao tiến hành một số hoạt động điều tra quyết định.

Nhìn chung thẩm quyền khởi tố bị can đối với pháp nhân theo Điều 179 BLTTHS năm 2015 thuộc về Thủ trưởng, Phó Thủ trưởng CQĐT các cấp; Viện trưởng, Phó Viện trưởng VKS nhân dân, VKS quân sự các cấp.

Tuy vậy, VKS các cấp chỉ khởi tố bị can đối với pháp nhân hoặc cá nhân trong trường hợp: i) Phát hiện có người đã thực hiện hành vi mà BLHS quy định là tội phạm chưa bị khởi tố thì VKS yêu cầu CQĐT ra quyết định khởi tố bị can hoặc trực tiếp ra quyết định khởi tố bị can nếu đã yêu cầu nhưng CQĐT không thực hiện; ii) Sau khi nhận hồ sơ và kết luận điều tra, nếu VKS phát hiện có người khác đã thực hiện hành vi mà BLHS năm 2015 quy định là tội phạm trong vụ án chưa bị khởi tố thì VKS ra quyết định khởi tố bị can và trả hồ sơ cho CQĐT để điều tra bổ sung.

Ngoài CQĐT và VKS, khi tiến hành tố tụng đối với tội phạm ít nghiêm trọng trong trường hợp phạm tội quả tang, chứng cứ và lí lịch người phạm tội rõ ràng, những người có chức vụ trong các cơ quan được giao nhiệm vụ tiến hành một số hoạt động điều tra cũng có thẩm quyền quyết định khởi tố bị can đối với cá nhân và pháp nhân phạm tội (Khoản 2 Điều 39 BLTTHS năm 2015), đó là những người trong các cơ quan:
+ Bộ đội biên phòng gồm Cục trưởng, Phó Cục trưởng Cục Trinh sát Biên phòng; Cục trưởng, Phó Cục trưởng Cục phòng, chống ma túy và tội phạm; Đoàn trưởng, Phó Đoàn trưởng Đoàn đặc nhiệm phòng, chống ma túy và tội phạm; Chỉ huy trưởng, Phó Chỉ huy trưởng Bộ đội biên phòng tỉnh, thành phố trực thuộc trung ương; Đồn trưởng, Phó Đồn trưởng Đồn biên phòng; Chỉ huy trưởng, Phó Chỉ huy trưởng Biên phòng Cửa khẩu cảng;

+ Hải quan gồm Cục trưởng, Phó Cục trưởng Cục Điều tra chống buôn lậu; Cục trưởng, Phó Cục trưởng Cục kiểm tra sau thông quan; Cục trưởng, Phó Cục trưởng Cục Hải quan tỉnh, liên tỉnh, thành phố trực thuộc trung ương; Chi cục trưởng, Phó Chi cục trưởng Chi cục Hải quan cửa khẩu;

+ Kiểm lâm gồm Cục trưởng, Phó Cục trưởng Cục Kiểm lâm; Chi cục trưởng, Phó Chi cục trưởng Chi cục Kiểm lâm; Hạt trưởng, Phó Hạt trưởng Hạt Kiểm lâm;

+ Cảnh sát biển gồm Tư lệnh, Phó Tư lệnh Cảnh sát biển; Tư lệnh vùng, Phó Tư lệnh vùng Cảnh sát biển; Cục trưởng, Phó Cục trưởng Cục Nghiệp vụ và pháp luật; Đoàn trưởng, Phó Đoàn trưởng Đoàn đặc nhiệm phòng, chống tội phạm ma túy; Hải đoàn trưởng, Phó Hải đoàn trưởng; Hải đội trưởng, Phó Hải đội trưởng; Đội trưởng, Phó Đội trưởng Đội nghiệp vụ Cảnh sát biển;

+ Kiểm ngư gồm Cục trưởng, Phó Cục trưởng Cục Kiểm ngu; Chi Cục trưởng, Phó Chi cục trưởng Chi cục Kiểm ngư vùng.

Khoản 2 Điều 433 BLTTHS năm 2015 quy định cũng tương tự như Khoản 2 Điều 179 của Bộ luật này, đó là quyết định khởi tố bị can đối với pháp nhân phải ghi rõ thời gian, địa điểm ra quyết định; họ tên, chức vụ người ra quyết định; tên và địa chỉ của pháp nhân theo quyết định thành lập của cơ quan có thẩm quyền; tội danh, điều khoản của BLHS năm 2015 đã áp dụng; thời gian, địa điểm phạm tội và những tình tiết khác của tội phạm.

Nếu pháp nhân bị khởi tố về nhiều tội khác nhau thì trong quyết định khởi tố bị can đối với 
pháp nhân phải ghi rõ từng tội danh và điều, khoản của BLHS năm 2015 được áp dụng.

Về trình tự, thủ tục khởi tố bị can đối với pháp nhân được quy định chung như bị can đối với khởi tố cá nhân, cụ thể như sau:

Kể từ khi ra quyết định khởi tố bị can, trong thời hạn 24 giờ CQĐT phải gửi quyết định khởi tố và tài liệu liên quan đến việc khởi tố bị can cho VKS cùng cấp để xét phê chuẩn. Trong thời hạn 03 ngày kể từ ngày nhận được quyết định khởi tố bị can, VKS phải quyết định phê chuẩn hoặc quyết định hủy bỏ quyết định khởi tố bị can hoặc yêu cầu bổ sung chứng cứ, tài liệu làm căn cứ để quyết định việc phê chuẩn và gửi ngay cho CQĐT.

Trường hợp VKS yêu cầu bổ sung chứng cứ, tài liệu thì trong thời hạn 03 ngày kể từ ngày nhận được chứng cứ, tài liệu bố sung, VKS phải ra quyết định phê chuẩn hoặc quyết định hủy bỏ quyết định khởi tố bị can.

Sau khi nhận được quyết định phê chuẩn quyết định khởi tố bị can hoặc quyết định khởi tố bị can của VKS, CQĐT phải giao ngay quyết định khởi tố bị can, quyết định phê chuẩn quyết định khởi tố bị can và giải thích quyền, nghĩa vụ cho bị can là pháp nhân thông qua người đại diện theo pháp luật của pháp nhân. Việc giao, nhận các quyết định nêu trên được lập biên bản theo quy định tại Điều 133 của BLTTHS năm 2015.

\subsection{Thay đổi, bổ sung quyết định khởi tố bị can đối với pháp nhân}

Khi tiến hành điều tra nếu có căn cứ xác định hành vi của bị can không phạm vào tội đã bị khởi tố hoặc quyết định khởi tố ghi không đúng họ, tên, tuồi, nhân thân của bị can thì CQĐT, VKS ra quyết định thay đổi quyết định khởi tố bị can đối với pháp nhân.

Trong trường hợp khi tiến hành điều tra có đủ chứng cứ xác định bị can là pháp nhân còn thực hiện hành vi khác mà BLHS quy định là tội phạm thì CQĐT, VKS phải bổ sung quyết định khởi tố bị can đối với pháp nhân.
Mọi trường hợp thay đổi hoặc bổ sung quyết định khởi tố bị can đối với pháp nhân đều phải có sự phê chuẩn của VKS. Điều 180 BLTTHS năm 2015 quy định trong thời hạn 24 giờ kể từ khi ra quyết định thay đổi hoặc bổ sung quyết định khởi tố bị can, CQĐT phải gửi quyết định này và tài liệu có liên quan đến việc thay đổi hoặc bổ sung đó cho VKS cùng cấp để xét phê chuẩn. Trong thời hạn 03 ngày kể từ ngày nhận được quyết định thay đổi hoặc bổ sung quyết định khởi tố bị can, VKS phải quyết định phê chuẩn hoặc quyết định hủy bỏ quyết định thay đổi hoặc bổ sung quyết định khởi tố bị can hoặc yêu cầu bổ sung chứng cứ, tài liệu làm căn cứ để quyết định việc phê chuẩn và gửi ngay cho CQĐT.

Trường hợp VKS yêu cầu bổ sung chứng cứ, tài liệu thì trong thời hạn 03 ngày kể từ ngày nhận được chứng cứ, tài liệu bổ sung, VKS ra quyết định phê chuẩn hoặc hủy bỏ quyết định thay đổi hoặc bổ sung quyết định khởi tố bị can.

Sau khi nhận được quyết định phê chuẩn hoặc quyết định hủy bỏ quyết định thay đổi hoặc bổ sung quyết định khởi tố bị can là pháp nhân, quyết định thay đổi hoặc bổ sung quyết định khởi tố bị can là pháp nhân của VKS, CQĐT phải giao ngay quyết định này cho pháp nhân đã bị khởi tố thông qua người đại diện theo pháp luật của pháp nhân. Việc giao, nhận các quyết định nêu trên được lập biên bản theo quy định tại Điều 133 của BLTTHS năm 2015.

Đối với trường hợp VKS ra quyết định thay đổi hoặc bổ sung quyết định khởi tố bị can đối với pháp nhân, thì trong thời hạn 24 giờ kể từ khi ra quyết định đó VKS phải gửi cho CQĐT để tiến hành điều tra.

\section{Lấy lời khai người đại diện theo pháp luật của pháp nhân}

Sau khi khởi tố VAHS đối với pháp nhân, Điều tra viên, cán bộ điều tra của cơ quan được giao nhiệm vụ tiến hành một số hoạt động điều tra phải lấy lời khai của người đại diện theo pháp luật của pháp nhân để thu thập chứng cứ 
và làm rõ sự thật khách quan của vụ án đối với pháp nhân bị khởi tố.

Việc lấy lời khai của người đại diện theo pháp luật của pháp nhân phải tuân theo quy định tại Điều 442 BLTTHS năm 2015, đó là:

Điều tra viên, cán bộ điều tra phải có giấy triệu tập người đại diện theo pháp luật của pháp nhân để lấy lời khai. Giấy triệu tập phải ghi rõ họ tên, chỗ ở hoặc làm việc của người đại diện theo pháp luật của pháp nhân; giờ, ngày, tháng, năm, địa điểm có mặt, gặp ai và trách nhiệm về việc vắng mặt không vì lí do bất khả kháng hoặc không do trở ngại khách quan (Điều 440 BLTTHS năm 2015).

Trong khi Khoản 1 Điều 183 BLTTHS quy định đối với bị can là cá nhân, việc hỏi cung bị can do điều tra viên tiến hành ngay sau khi có quyết định khởi tố bị can, có thể hỏi cung bị can tại nơi tiến hành điều tra hoặc tại nơi ở của người đó thì đối với việc lấy lời khai của người đại diện theo pháp luật của pháp nhân phải được thực hiện tại nơi tiến hành điều tra, tại trụ sở CQĐT, cơ quan được giao nhiệm vụ tiến hành một số hoạt động điều tra hoặc tại trụ sở của pháp nhân.

Trước khi lấy lời khai, Điều tra viên, cán bộ điều tra phải thông báo cho Kiểm sát viên và người bào chữa thời gian, địa điểm lấy lời khai. Khi xét thấy cần thiết, Kiểm sát viên tham gia việc lấy lời khai.

Trước khi tiến hành lấy lời khai lần đầu, Điều tra viên, cán bộ điều tra của cơ quan được giao nhiệm vụ tiến hành một số hoạt động điều tra phải giải thích cho người đại diện theo pháp luật của pháp nhân biết rõ quyền và nghĩa vụ quy định tại Điều 435 của BLTTHS năm 2015 và phải ghi vào biên bản. Khi tiến hành lấy lời khai Điều tra viên hoặc cán bộ điều tra đưa ra những câu hỏi người đại diện theo pháp luật của pháp nhân những vấn đề liên quan đến vụ án, nhưng cũng có thể cho họ tự viết lời khai của mình.

Không được lấy lời khai người đại diện theo pháp luật của pháp nhân vào ban đêm, Điều 442 BLTTHS năm 2015 không có quy định trường hợp ngoại lệ. Trong khi đó đối với bị can là cá nhân trong trường hợp không thể trì hoãn được thì điều tra viên vẫn có thể hỏi cung về ban đêm và phải ghi rõ lí do vào biên bản (khoản 3 Điều 183 BLTTHS năm 2015). Khi lấy lời khai người đại diện theo pháp luật của pháp nhân không được dùng nhục hình, bức cung, mớm cung hoặc những biện pháp trái pháp luật khác đối với họ.

Trong trường hợp người đại diện theo pháp luật của pháp nhân không thừa nhận hành vi phạm tội của pháp nhân, khiếu nại hoạt động điều tra hoặc có căn cứ xác định việc điều tra vi phạm pháp luật hoặc trong trường hợp khác khi xét thấy cần thiết kiểm sát viên sẽ lấy lời khai người đại diện theo pháp luật của pháp nhân. kiểm sát viên lấy lời khai người đại diện theo pháp luật của pháp nhân cũng được tiến hành theo quy định như đối với điều tra viên, cán bộ điều tra cán bộ điều tra của cơ quan được giao nhiệm vụ tiến hành một số hoạt động điều tra lấy lời khai của người này.

Để bảo đảm thực hiện quyền con người, quyền công dân theo Hiến pháp 2013, tính khách quan, minh bạch trong hoạt động tố tụng, ngăn ngừa những hành vi vi phạm pháp luật của người tiến hành tố tụng, giúp cho cơ quan chức năng kiểm tra, phát hiện có hay không dấu hiệu oan, sai; bị can có bị bức cung hoặc dùng nhục hình hoặc vi phạm pháp luật trong giai đoạn điều tra hay không, khoản 6 Điều 183 và khoản 5 Điều 442 BLTTHS năm 2015 quy định việc ghi âm, ghi hình hoạt động hỏi cung bị can là cá nhân hoặc pháp nhân, đồng thời để bảo đảm tính khả thi, hiệu quả, tránh lãng phí, phù hợp với điều kiện nước ta. Điều 442 BLTTHS năm 2015 đã quy định việc lấy lời khai của người đại diện theo pháp luật của pháp nhân tại trụ sở CQĐT, cơ quan được giao nhiệm vụ tiến hành một số hoạt động điều tra phải được ghi âm hoặc ghi hình có âm thanh. Việc lấy lời khai của người đại diện theo pháp luật của pháp nhân tại các địa điểm khác được ghi âm hoặc ghi hình có âm thanh theo yêu cầu của người đại diện, của cơ quan, người có thẩm quyền tiến hành tố tụng $[5,6]$.

Điều tra viên, kiểm sát viên, cán bộ điều tra của cơ quan được giao nhiệm vụ tiến hành một 
số hoạt động điều tra lấy lời khai người đại diện theo pháp luật của pháp nhân đều phải lập biên bản theo quy định tại Điều 178 của BLTTHS năm 2015.

\section{Tạm đình chỉ điều tra, đình chỉ điều tra, đình chỉ vụ án, đình chỉ bị can, bị cáo là pháp nhân}

Tạm đình chỉ điều tra là việc cơ quan có thẩm quyền tiến hành tố tụng tạm ngừng điều tra đối với vụ án hoặc đối với bị can là pháp nhân khi có những căn cứ do BLTTHS năm 2015 quy định.

Theo quy định tại Điều 443 BLTTHS năm 2015, CQĐT, cơ quan được giao nhiệm vụ tiến hành một số hoạt động điều tra ra quyết định tạm đình chỉ điều tra khi trưng cầu giám định, yêu cầu định giá tài sản, yêu cầu nước ngoài tương trợ tư pháp nhưng chưa có kết quả mà đã hết thời hạn điều tra.

Trường hợp này việc giám định, định giá tài sản, tương trợ tư pháp vẫn tiếp tục được tiến hành cho đến khi có kết quả. Quy định này cho phép khi có kết quả giám định, định giá tài sản hoặc kết quả yêu cầu tương trợ tư pháp thì CQĐT, cơ quan được giao nhiệm vụ tiến hành một số hoạt động điều tra ra quyết định phục hồi điều tra hoặc đình chỉ điều tra nếu kết quả đó cho kết luận hành vi của pháp nhân không thỏa mãn các dấu hiệu cấu thành tội phạm theo quy định của BLHS.

Đình chỉ điều tra là việc cơ quan nhà nước có thẩm quyền tiến hành tố tụng chấm dứt toàn bộ hoạt động điều tra đối với vụ án và bị can là pháp nhân khi có căn cứ do BLTTHS năm 2015 quy định.

Đình chỉ vụ án, đình chỉ bị can, bị cáo là việc VKS hoặc Tòa án chấm dứt toàn bộ hoạt động truy tố xét xử vụ án và bị can, bị cáo khi có căn cứ do BLTTHS năm 2015 quy định.

Theo khoản 2 Điều 443 BLTTHS năm 2015, CQĐT, cơ quan được giao nhiệm vụ tiến hành một số hoạt động điều tra ra quyết định đình chỉ điều tra, VKS, Tòa án ra quyết định đình chỉ vụ án, đình chỉ bị can, bị cáo là pháp nhân khi thuộc một trong các trường hợp: a) Không có sự việc phạm tội; b) Hành vi của pháp nhân không cấu thành tội phạm; c) Hành vi phạm tội của pháp nhân đã có bản án hoặc quyết định đình chỉ vụ án có hiệu lực pháp luật; d) Hết thời hạn điều tra mà không chứng minh được pháp nhân thực hiện tội phạm; đ) Hết thời hiệu truy cứu trách nhiệm hình sự.

Khoản 2 Điều 443 BLTTHS năm 2015 không tách các căn cứ để VKS ra quyết định đình chỉ vụ án, đình chỉ bị can và các căn cứ để Tòa án ra quyết định đình chỉ vụ án, đình chỉ bị cáo, dẫn đến không thống nhất giữa các quy định về đình chỉ vụ án theo thủ tục thông thường và thủ tục đối với pháp nhân.

Đối với các quy định về đình chỉ vụ án theo thủ tục thông thường, Thẩm phán Chủ tọa phiên tòa chỉ được đình chỉ vụ án trong giai đoạn chuẩn bị xét xử nếu có căn cứ quy định tại Điều 282 BLTTHS năm 2015, đó là: i) Có một trong các căn cứ quy định tại khoản 2 Điều 155 hoặc các điểm $3,4,5,6$ và 7 Điều 157 của BLTTHS năm 2015; ii) VKS rút toàn bộ quyết định truy tố trước khi mở phiên tòa.

So sánh với quy định về những căn cứ không khởi tố VAHS theo Điều 157 BLTTHS năm 2015 thì trong giai đoạn chuẩn bị xét xử khi có căn cứ không có sự việc phạm tội, hành vi không cấu thành tội phạm Thẩm phán Chủ tọa phiên tòa cũng không được quyết định đình chỉ vụ án, vì đó không phải là căn cứ để họ được phép đình chỉ vụ án. Trong khi đó theo Khoản 2 Điều 443 BLTTHS năm 2015 thì đó lại là căn cứ để Tòa án đình chỉ vụ án, đình chỉ bị cáo.

\section{Xét xử vụ án hình sự đối với pháp nhân}

\subsection{Thẩm quyền xét xư so thẩm đối với pháp nhân}

Theo quy định của BLTTHS năm 2015 về thẩm quyền xét xử sơ thẩm đối với pháp nhân gồm những quy định chung về thẩm quyền theo sự việc và đối tượng, quy định riêng đối với pháp nhân về thẩm quyền theo lãnh thổ. 


\subsubsection{Thẩm quyền xét xử theo lãnh thổ}

Theo Điều 444 BLTTHS năm 2015 thẩm quyền xét xử sơ thẩm theo lãnh thổ đối với pháp nhân được phân định theo nơi pháp nhân thực hiện tội phạm hoặc nơi pháp nhân có trụ sở chính hoặc có chi nhánh.

i) Tòa án nơi pháp nhân thực hiện tội phạm

Theo khoản 1 Điều 444 BLTTHS năm 2015, Tòa án có thẩm quyền xét xử VAHS về các tội phạm do pháp nhân thực hiện là Tòa án nơi pháp nhân thực hiện tội phạm. Như vậy, những tội phạm do pháp nhân thực hiện xảy ra ở nơi nào, địa phận hành chính lãnh thổ thuộc Tòa án nào thì Tòa án đó có thẩm quyền xét xử. Thẩm quyền tố tụng của Tòa án theo nơi thực hiện tội phạm là quy định có tính nguyên tắc, bảo đảm xét xử được thuận lợi, khách quan và phù hợp với chuyên môn, nghiệp vụ cũng như các điều kiện vật chất phục vụ cho hoạt động xét xử của Tòa án. Quy định này phù hợp với quy định về thẩm quyền theo lãnh thổ của Tòa án theo thủ tục thông thường (Khoản 1 Điều 269 BLTTHS năm 2015) và Khoản 4 Điều 163 BLTTHS năm 2015 khi quy định về thẩm quyền của cơ quan điều tra, theo đó $\mathrm{CQĐT}$ có thẩm quyền điều tra những VAHS mà tội phạm xảy ra trên địa phận của mình.

ii) Tòa án nơi pháp nhân có trụ sở chính hoặc có chi nhánh

Trong trường hợp tội phạm thực hiện tại nhiều nơi khác nhau hoặc không xác định được nơi thực hiện tội phạm thì Tòa án có thẩm quyền xét xử là "Tòa án nơi pháp nhân đó có trụ sở chính hoặc nơi có chi nhánh của pháp nhân đó thực hiện tội phạm"(khoản 1 Điều 444 BLTTHS năm 2015).

Đối với những tội phạm thực hiện tại nhiều nơi khác nhau, đó có thể là những trường hợp phạm tội từ hai lần trở lên, phạm nhiều tội hoặc phạm một tội bởi nhiều hành vi khách quan được thực hiện ở nhiều địa phương khác nhau, cũng như trường hợp không xác định được nơi thực hiện tội phạm thì việc quy định thẩm quyền xét xử theo nơi pháp nhân có trụ sở chính hoặc có chi nhánh là phù hợp với đặc điểm của pháp nhân, bảo đảm cho việc xét xử của Tòa án được thuận lợi.

5.1.2. Thẩm quyền xét xủ theo sụ việc và theo đối tượng

Điều 444 BLTTHS năm 2015 không quy định riêng về thẩm quyền xét xử sơ thẩm theo sự việc và theo đối tượng đối với pháp nhân. Theo Điều 431 BLTTHS năm 2015, thẩm quyền xét xử sơ thẩm theo sự việc và theo đối tượng đối với pháp nhân được thực hiện theo các quy định chung (các điều 268, 271, 272, 273 BLTTHS năm 2015).

5.2. Xét xử so thẩm, phúc thẩm, giám đốc thẩm, tái thẩm

Theo quy định tại Khoản 2 Điều 444 BLTTHS năm 2015 việc xét xử sơ thẩm, phúc thẩm; xét lại bản án, quyết định đã có hiệu lực pháp luật đối với pháp nhân được thực hiện theo thủ tục chung trong BLTTHS năm 2015 theo quy định tại Phần thứ tư: Xét xử VAHS, từ chương XX đến chương XXIII và Phần thứ sáu: Xét lại bản án, quyết định có hiệu lực pháp luật, từ chương $\mathrm{XXV}$ đến chương XXVII.

Cũng theo quy định ở Khoản 2 Điều 444 BLTTHS năm 2015 phiên tòa xét xử đối với pháp nhân phải có mặt của người đại diện theo pháp luật của pháp nhân, kiểm sát viên VKS cùng cấp; có mặt người bị hại hoặc người đại diện người bị hại.

Theo quy định này thì sự có mặt của người đại diện theo pháp luật của pháp nhân tại phiên tòa là bắt buộc, người này phải có mặt theo giấy triệu tập của Tòa án, trường hợp vắng mặt không vì lí do bất khả kháng hoặc do trở ngại khách quan thì Tòa án có thể ra quyết định dẫn giải.

Cũng giống như phiên tòa xét xử theo thủ tục thông thường, tại phiên tòa xét xử pháp nhân, sự có mặt của kiểm sát viên VKS là bắt buộc, vì kiểm sát viên thay mặt VKS duy trì quyền công tố, buộc tội bị cáo trước Tòa án, nên nếu kiểm sát viên vắng mặt thì phải hoãn phiên tòa xét xử. 
Phiên tòa xét xử pháp nhân cũng phải có mặt của người bị hại hoặc người đại diện hợp pháp của họ. Theo Điều 292 BLTTHS năm 2015, nếu bị hại hoặc người đại diện của họ vắng mặt thì tùy trường hợp, Hội đồng xét xử quyết định hoãn phiên tòa hoặc vẫn tiến hành xét xử. Trường hợp xét thấy sự vắng mặt của bị hại hoặc người đai diện của ho chỉ trở ngai cho việc giải quyết bồi thường thiệt hại thì Hội đồng xét xử có thể tách việc bồi thường để xét xử sau theo quy định của pháp luật.

\section{Thẩm quyền, thủ tục thi hành án đối với pháp nhân}

Điều 33 BLHS năm 2015 quy định hệ thống hình phạt áp dụng đối với pháp nhân phạm tội, trong đó các hình phạt chính gồm có: i) Phạt tiền; ii) Đình chỉ hoạt động có thời hạn; iii) Đình chỉ hoạt động vĩnh viễn. Hình phạt bổ sung bao gồm: i) Cấm kinh doanh, cấm hoạt động trong một số lĩnh vực nhất định;ii) Cấm huy động vốn; iii) Phạt tiền, khi không áp dụng là hình phạt chính. Bên cạnh hệ thống hình phạt, BLHS năm 2015 cũng quy đinh các biện pháp tư pháp áp dụng đối với pháp nhân, đó là: i) Tịch thu vật, tiền trực tiếp liên quan đến tội phạm; ii) Trả lại tài sản, sửa chữa hoặc bồi thường thiệt hại; buộc công khai xin lỗi; iii) Khôi phục lại tình trạng ban đầu; iv) Thực hiện một số biện pháp nhằm khắc phục, ngăn chặn hậu quả tiếp tục xảy ra.

Trong số các tội phạm cụ thể quy kết cho pháp nhân được quy định tại 33 điều luật về tội phạm trong phần Các tội phạm BLHS năm 2015, đều quy định hình phạt chính là phạt tiền là hình phạt chủ yếu. Đồng thời, phạt tiền với tư cách là hình phạt chính hoặc là hình phạt bổ sung đều được quy định áp dụng cho cả người phạm tội và pháp nhân phạm tội nên việc thi hành hình phạt này được quy định rõ tại Điều 445 BLTTHS năm 2015 là: Thủ trưởng cơ quan thi hành án dân sự có thẩm quyền ra quyết định thi hành hình phạt tiền đối với pháp nhân.
Trình tự, thủ tục thi hành hình phạt tiền được thực hiện theo quy định của Luật thi hành án dân sự và được quy định như sau:

Theo Điều 36 Luật thi hành án dân sự năm 2008 (sửa đổi năm 2014), trong thời hạn 05 ngày làm việc, kể từ ngày nhận được bản án, quyết định của Tòa án, Thủ trưởng cơ quan thi hành án dân sự phải ra quyết định thi hành án phạt tiền đối với pháp nhân. Trong thời hạn 02 ngày làm việc, kể từ ngày ra quyết định thi hành án, Thủ trưởng cơ quan thi hành án dân sự phải phân công chấp hành viên tổ chức thi hành quyết định thi hành án. Quyết định thi hành án phải gửi cho VKS cùng cấp để thực hiện chức năng kiểm sát việc tuân theo pháp luật trong thi hành án (Điều 38). Quyết định về thi hành án, giấy báo, giấy triệu tập và văn bản khác có liên quan đến việc thi hành án phải được giao trực tiếp cho người đại diện theo pháp luật hoặc người chịu trách nhiệm nhận văn bản của cơ quan, tổ chức đó và phải được những người này kí nhận. Trường hợp cơ quan, tổ chức được thông báo có người đại diện tham gia việc thi hành án hoặc cử người đại diện nhận văn bản thông báo thì những người này kí nhận văn bản thông báo. Ngày kí nhận là ngày được thông báo hợp lệ (Điều 41). Trường hợp chủ động ra quyết định thi hành án, chấp hành viên phải tiến hành xác minh điều kiện thi hành án của người phải thi hành án. Thời hạn tự nguyện thi hành án là 15 ngày, kể từ ngày pháp nhân bị kết án nhận được hoặc được thông báo hợp lệ quyết định thi hành án. Hết thời hạn này, pháp nhân bị thi hành án có điều kiện thi hành án mà không tự nguyện thi hành án thì bị cưỡng chế. Việc thi hành án đương nhiên kết thúc trong các trường hợp sau đây: i) Đương sự đã thực hiện xong quyền, nghĩa vụ của mình; ii) Có quyết định đình chỉ thi hành án; iii) Có quyết định trả đơn yêu cầu thi hành án.

Cơ quan nhà nước có thẩm quyền thi hành các hình phạt khác và các biện pháp tư pháp quy định tại BLHS năm 2015 đối với pháp nhân theo quy định của pháp luật thi hành án hình sự. 
Trường hợp pháp nhân bị kết án thực hiện chia, tách, hợp nhất, sáp nhập thì pháp nhân kế thừa các quyền và nghĩa vụ của pháp nhân bị kết án có trách nhiệm thực hiện nghĩa vụ thi hành án phạt tiền, bồi thường thiệt hại.

\section{Thủ tục đương nhiên xóa án tích đối với pháp nhân}

Xóa án tích là một chế định tiến bộ, nhân đạo. Người và pháp nhân được xóa án tích được coi là chưa bị kết án. Án tích đã xóa không được tính để xác định tái phạm, tái phạm nguy hiểm.

Đối với cá nhân phạm tội bị kết án, BLHS năm 2015 quy định hai hình thức xóa án tích: Đương nhiên được xóa án tích và xóa án tích do Tòa án quyết định. Nhưng đối với pháp nhân bị kết án thì chỉ áp dụng hình thức đương nhiên được xóa án tích.

Điều kiện pháp nhân bị kết án được đương nhiên xóa án tích là nếu trong thời hạn 02 năm kể từ khi chấp hành xong hình phạt chính, hình phạt bổ sung, các quyết định khác của bản án hoặc từ khi hết thời hiệu thi hành bản án mà pháp nhân không thực hiện hành vi phạm tội mới.

Khi có đủ điều kiện như trên, pháp nhân làm đơn yêu cầu xóa án tích. Trong thời hạn 05 ngày kể từ ngày nhận được yêu cầu của pháp nhân được đương nhiên xóa án tích và xét thấy có đủ điều kiện nêu trên theo quy định tại Điều 89 của BLHS năm 2015 thì Chánh án Tòa án đã xét xử sơ thẩm vụ án cấp giấy chứng nhận pháp nhân đã được xóa án tích.

\section{Một số kiến nghị tiếp tục hoàn thiện các quy định đặc thù về thủ tục tố tụng đối với pháp nhân}

Trên cơ sở các kết quả nghiên cứu những quy định đặc thù về thủ tục tố tụng hình sự đối với pháp nhân trong BLTTHS năm 2015 tác giả có một số kiến nghị sau:
Thư nhất, BLHS năm 2015 (sửa đổi năm 2017) chỉ quy định TNHS của pháp nhân thương mại, trong khi đó BLTTHS năm 2015 lại quy định trình tự, thủ tục tố tụng đối với pháp nhân nói chung. Vì vậy, BLTTHS năm 2015 cần sửa đổi lại cho thống nhất với BLHS năm 2015.

Thú hai, đối với các quy định về đình chỉ vụ án theo thủ tục thông thường, tức là đối với người bị buộc tội, Thẩm phán Chủ tọa phiên tòa chỉ được đình chỉ vụ án trong giai đoạn chuẩn bị xét xử nếu có căn cứ quy định tại Điều 282 BLTTHS năm 2015, đó là: i) Có một trong các căn cứ quy định tại Khoản 2 Điều 155 hoặc các điểm 3, 4, 5, 6 và 7 Điều 157 của BLTTHS năm 2015; ii) VKS rút toàn bộ quyết định truy tố trước khi mở phiên tòa. Như vậy, trong giai đoạn chuẩn bị xét xử khi có căn cứ không có sụ việc phạm tội hoạc hành vi không cấu thành tội phạm Thẩm phán Chủ tọa phiên tòa không được quyết định đình chỉ vụ án, vì đó không phải là căn cứ để họ được phép đình chỉ vụ án. Trong khi đó, Khoản 2 Điều 443 BLTTHS năm 2015 không tách các căn cứ để VKS ra quyết định đình chỉ vụ án, đình chỉ bị can và các căn cứ để Tòa án ra quyết định đình chỉ vụ án, đình chỉ bị cáo, nên dẫn đến tình trạng không có sự thống nhất giữa các quy định về đình chỉ vụ án theo thủ tục thông thường đối với người phạm tội và thủ tục đối với pháp nhân, dẫn đến trường hợp có một trong hai căn cứ nêu trên, trong giai đoạn chuẩn bị xét xử, Thẩm phán Chủ tọa phiên tòa có thẩm quyền quyết định đình chỉ vụ án, đình chỉ bị cáo. Tác giả cho rằng trong giai đoạn chuẩn bị xét xử nên quy định các căn cứ để Tòa án ra quyết định đình chỉ vụ án, đình chỉ bị cáo đối pháp nhân giống như đối với pháp nhân, nhất là trong trường hợp cả cá nhân người phạm tội và cá nhân bị điều tra, truy tố, xét xử trong cùng vụ án về cùng một tội phạm. Trong giai đoạn xét xử, Tòa án không vận dụng một trong hai căn cứ không có sư việc phạm tộ hoạc hành vi không cấu thành tội phạm để đình chỉ vụ án là vì theo nhân định của $\mathrm{CQĐT} \mathrm{và}$ VKS đã có sự việc phạm tội xảy ra hoặc hành vi đã cấu thành tội phạm. Cho nên, Tòa án xác định sự việc đó không phải là sự việc phạm tội 
hoặc hành vi không cấu thành tội phạm thì phải mở phiên tòa xét xử. Sau khi đưa ra các chứng cứ chứng minh quan điểm của mình, Tòa án sẽ tuyên bố vô tội [7].

Thư $b a$, khi nghiên cứu thẩm quyền theo lãnh thổ của Tòa án trong mối liên hệ với thẩm quyền của $\mathrm{CQ} Đ T, \mathrm{VKS}$ theo những quy định chung được quy định trong BLTTHS năm 2015 đối với trường hợp tội phạm thực hiện tại nhiều nơi khác nhau hoặc không xác định được địa điểm xảy ra tội phạm cho thấy nổi lên một số vấn đề sau:

Một là, thẩm quyền truy tố của VKS được xác định theo thẩm quyền xét xử của Tòa án đối với vụ án (đoạn 1 khoản 1 Điều 239 BLTTHS năm 2015). Như vậy, đối với trường hợp tội phạm thực hiện tại nhiều nơi khác nhau hoặc không xác định được địa điểm xảy ra tội phạm thì thẩm quyền xét xử của Tòa án và thẩm quyền truy tố của VKS là nơi có trụ sở chính hoặc có chi nhánh của pháp nhân.

Hai là, trường hợp tội phạm được thực hiện tại nhiều nơi khác nhau hoặc không xác định được địa điểm xảy ra tội phạm thì việc điều tra thuộc thẩm quyền của CQĐT nơi phát hiện tội phạm, nơi bị can cư trú hoặc bị bắt (Khoản 4 Điều 163 BLTTHS năm 2015). Theo quy định trên, thẩm quyền xét xử theo lãnh thổ của Tòa án không phải là cơ sở xác định thẩm quyền điều tra của CQĐT như là trường hợp thẩm quyền truy tố của VKS. Quy định tại Khoản 4 Điều 163 BLTTHS năm 2015 nêu trên chỉ là quy định thẩm quyền điều tra theo lãnh thổ đối với cá nhân người phạm tội, chứ không phải là quy định thẩm quyền điều tra theo lãnh thổ đối với pháp nhân trong trường hợp tội phạm thực hiện tại nhiều nơi khác nhau hoặc không xác định được địa điểm xảy ra tội phạm. BLTTHS năm 2015 cần phải bổ sung thêm quy định là trường hợp không xác định được địa điểm xảy ra tội phạm hoặc tội phạm được thực hiện tại nhiều nơi khác nhau thì việc điều tra thuộc thẩm quyền của CQĐT nơi pháp nhân có trụ sở chính hoặc nơi có chi nhánh của pháp nhân thực hiện tội phạm.
Bên cạnh đó, BLTTHS năm 2015 cũng chưa có quy định thẩm quyền xét xử sơ thẩm theo lãnh thổ đối với cả cá nhân người phạm tội và pháp nhân trong cùng vụ án. Trong trường hợp thành viên là người đại diện theo pháp luật của pháp nhân hoặc những thành viên khác của pháp nhân đã thực hiện hành vi phạm tội nhân danh pháp nhân, vì lợi ích của pháp nhân, thực hiện tội phạm theo sự lãnh đạo, điều hành hoặc có sự chấp thuận của pháp nhân và hành vi phạm tội đó chưa hết thời hiệu truy cứu TNHS thì không chỉ cá nhân thành viên đó phải chịu TNHS mà pháp nhân cũng phải chịu TNHS về cùng tội phạm do thành viên của pháp nhân đó thực hiện. Như vậy, pháp nhân phạm tội thông qua trung gian hành vi phạm tội của cá nhân thành viên của pháp nhân. Vì thế, Khoản 2 Điều 75 BLHS năm 2015 quy định việc pháp nhân chịu TNHS không loại trừ TNHS của cá nhân. Hành vi phạm tội của cá nhân được đồng nhất hóa với hành vi phạm tội của pháp nhân, nên chúng có quan hệ rất chặt chẽ, không tách rời nhau. Vì vậy, trong trường hợp này BLTTHS năm 2015 cần bổ sung quy định nhập vụ án để điều tra, truy tố đối với cá nhân người phạm tội và pháp nhân trong cùng vụ án. Đồng thời cũng bổ sung thêm quy định trong trường hợp cá nhân người phạm tội và pháp nhân bị khởi tố, điều tra, truy tố, xét xử trong cùng vụ án thì thẩm quyền điều tra của CQĐT theo như quy định tại Khoản 4 Điều 163 BLTTHS năm 2015.

Thư tư, trong số các hình phạt quy định áp dụng với pháp nhân phạm tội có hình phạt chính và hình phạt bổ sung: Đình chỉ hoạt động có thời hạn; Đình chỉ hoạt động vĩnh viễn; Cấm kinh doanh, cấm hoạt động trong một số lĩnh vực nhất định; Cấm huy động vôn; Khôi phục lại tình trạng ban đầu là những hình phạt chỉ được áp dụng đối với pháp nhân, không áp dụng với cá nhân phạm tội nên chưa có quy định cụ thể về thi hành những hình phạt này trong Luật thi hành án hình sự hoặc dân sự hiện hành. Vì vậy, trong thời gian tới cần sửa đổi, bổ sung các luật này để có cơ sở pháp lí thi hành các hình phạt cũng như biện pháp tư pháp đối với pháp nhân bị kết án. 
Thư năm, quy định về thủ tục đương nhiên xóa án tích đối với pháp nhân quy định tại Điều 446 BLTTHS năm 2015 không đồng bộ, thống nhất với quy định tại Điều 70 BLHS. Khoản 4 Điều 70 BLHS quy định: "Cơ quan quản lí cơ sở dữ liệu lí lịch tư pháp có trách nhiệm cập nhật thông tin về tình hình án tích của người bị kết án và khi có yêu cầu thì cấp phiếu lí lịch tư pháp xác nhận không có án tích, nếu có đủ điều kiện quy định tại khoản 2 hoặc khoản 3 Điều này". Theo quy định này Cơ quan quản lí cơ sở dữ liệu lí lịch tư pháp mới có trách nhiệm cấp phiếu lí lịch tư pháp xác nhận không có án tích cho người và pháp nhân bị kết án, nếu có đủ điều kiện theo quy định của BLHS năm 2015. BLTTHS năm 2015 cần quy định theo hướng Cơ quan quản lí cơ sở dữ liệu lí lịch tư pháp chứ không phải Chánh án Tòa án đã xét xử sơ thẩm vụ án cấp giấy chứng nhận pháp nhân đã được xóa án tích.

\section{Tài liệu tham khảo}

[1] Xem Trịnh Quốc Toản, Trách nhiệm hình sự của pháp nhân trong pháp luật hình sự, NXB Chính trị Quốc gia - Sự thật, Hà Nội, 2011; Trịnh Quốc Toản, Một số vấn đề về TNHS của pháp nhân trong Luật hình sự của các nước theo truyền thống Common Law, Tạp chí Toà án, số 18/9-2006, tr. 29-38; Trịnh Quốc Toản, Trách nhiệm hình sự của pháp nhân trong Luật hình sự các nước châu Âu lục địa, Tạp chí Nhà nước \& Pháp luật, số 6 (194)/2005; Trịnh Quốc Toản, Trách nhiệm hình sự của pháp nhân và mô hình của nó trong LHS Việt Nam tương lai, Tạp chí Nhà nước \& Pháp luật, số 5(217)/2006, tr. 50-62.

[2] Ủy ban thường vụ Quốc hội, Báo cáo giải trình tiếp thu, chỉnh lí dự thảo Bộ luật hình sự (sửa đổi), Tài liệu kỳ họp thứ 10 Quốc hội khóa XIII, $10 / 2015$;

[3] Xem Trịnh Quốc Toản, Nghiên cứu một số quy định đặc thù về thủ tục tố tụng hình sự đối với pháp nhân trong Bộ luật tố tụng hình sự năm 2015, Tạp chí Khoa học ĐHQGHN, Luật học, Tập 34, Số 3(2018), tr. 11-25;

[4] Xem PGS. TS. Nguyễn Văn Huyên, TS. Lê Lan Chi đồng chủ biên, Bình luận khoa học Bộ luật tố tụng hình sự năm 2015 (Thực hiện từ 01/7/2016), Nxb Lao động, 2016, tr. 527;

[5] Ủy ban Thường vụ Quốc hội, Báo cáo tiếp thu, giải trình ý kiến các vị đại biểu Quốc hội về dự án Bộ luật tố tụng hình sự (sửa đổi), Tài liệu kì họp thứ 10 Quốc hội khóa XIII, 11/2015.

[6] Xem Thông tư liên tịch số 03/2018/TTLT-BCAVKSNDTC-TANDTC-BQP ngày 1/2/2018 do Bộ trưởng Bộ Công an, Viện trưởng VKSNDTC, Chánh án TANDTC, Bộ trưởng Bộ Quốc phòng ban hành hướng dẫn về trình tự; thủ tục thực hiện ghi âm hoặc ghi hình có âm thanh; sử dụng, bảo quản, lưu trữ kết quả ghi âm hoặc ghi hình có âm thanh trong quá trình điều tra, truy tố, xét xử;

[7] Xem PGS. TS Nguyễn Ngọc Chí (chủ biên), Giáo trình Luật tố tụng hình sự Việt Nam, NXB Đại học Quốc gia Hà Nội, 2013, tr. 385-386. 


\title{
A Study of Particular Provisions on the Periods of Criminal Proceedings against Corporate Bodies in Criminal Procedure Code 2015
}

\author{
Trinh Quoc Toan \\ VNU School of Law, 144 Xuan Thuy, Cau Giay, Hanoi, Vietnam
}

\begin{abstract}
To better prevent crimes, the Vietnamese state has for the first time established commercial corporate bodies' criminal liability stipulated in Criminal Procedure Code 2015 (amended in 2017). This Code also provides procedures to prosecute corporate bodies. The paper investigates and analyses the provisions of Criminal Procedure Code 2015 regarding criminal procedures against corporate bodies in order to point out shortcomings and recommend amendments. This paper is a continuation of the article published in VNU Journal of Science - Legal Studies Vol 34, No.3 (2018).

Keywords: Criminal proceedings, Criminal Procedure Code 2015, commercial corporate bodies, criminal liability of corporate bodies.
\end{abstract}

